\title{
Low cycle fatigue behaviour of Ti-6Al-5Zr-0.5Mo-0.25Si alloy at room temperature
}

\author{
ANIL KUMAR NAG, K V U PRAVEEN and VAKIL SINGH* \\ Department of Metallurgical Engineering, Banaras Hindu University, Varanasi 221 005, India
}

MS received 30 December 2005; revised 30 March 2006

\begin{abstract}
Low cycle fatigue (LCF) behaviour of the near $\alpha$ titanium alloy, Ti-6Al-5Zr-0.5Mo-0.25Si (LT26A), was investigated in the $(\alpha+\beta)$ as well as $\beta$ treated conditions at room temperature. LCF tests were carried out under total strain controlled mode in the range of $\Delta \varepsilon_{t} / 2$ : from $\pm 0.60 \%$ to $\pm 1.40 \%$. The alloy shows cyclic softening in both the conditions. Also it exhibits dual slope Coffin-Manson $(\mathrm{C}-\mathrm{M})$ relationship in both the treated conditions.
\end{abstract}

Keywords. Titanium alloy, LT26A; low cycle fatigue; Coffin-Manson relationship; cyclic softening.

\section{Introduction}

Indigenously manufactured near- $\alpha$ titanium alloy, $\mathrm{Ti}-$ $6 \mathrm{Al}-5 \mathrm{Zr}-0 \cdot 5 \mathrm{Mo}-0 \cdot 25 \mathrm{Si}$ (LT26A), is closely similar to the near- $\alpha$ alloy, IMI685, designed for high temperature applications as compressor disc material in aero engines up to service temperature of $793 \mathrm{~K}$. It is characterized by predominantly $\alpha$ phase microstructure. Aluminum addition enhances creep resistance at elevated temperatures. Solubility of $\beta$ stabilizing element, Mo, in $\alpha$ titanium is low and its small addition to the LT26A alloy is essentially made to improve its tensile strength both at room temperature as well as at elevated temperatures. Small addition of silicon, also held in solid solution in the $\alpha$ phase, enhances tensile strength as well as creep strength at temperatures above $673 \mathrm{~K}$ (Flower et al 1971). Near- $\alpha$ characteristics of this alloy permit it to be hot worked at $\geq 1323 \mathrm{~K}$ and heat treated in the $\beta$ phase field without the risk of room temperature embrittlement encountered in other titanium alloys processed in this way. Apart from creep strength, a high resistance against low cycle fatigue is also demanded in view of the loading conditions of compressor discs in service. Microstructures of many near- $\alpha$ titanium alloys like IMI685 (Eylon and Hall 1977) and Ti-11 (Eylon and Bania 1978) have been shown to exert marked influence on their low cycle fatigue resistance. The present investigation deals with room temperature LCF behaviour of the alloy, LT26A, in the as received as well as $\beta$ treated conditions.

\footnotetext{
*Author for correspondence (vakil@ bhu.ac.in)
}

\section{Experimental}

The experimental alloy, LT26A, was procured from the Defence Metallurgical Research Laboratory (DMRL), Hyderabad, in the form of blanks of square cross-section $(15 \times 15 \times 130 \mathrm{~mm})$, supplied by MIDHANI, Hyderabad. The chemical composition of the alloy along with that of IMI685 is given in table 1. It may be seen that while concentration of most of the elements is almost comparable in the two alloys, that of $\mathrm{Al}$ and $\mathrm{Zr}$ is relatively higher in the alloy, LT26A. Carbon content, on the other hand, is nearly double in the alloy, IMI685, as compared to that in the alloy, LT26A. While the as-received condition refers to forging in the $\beta$ phase field and solution treatment in the $\alpha+\beta$ phase field at $1253 \mathrm{~K}$ for $1 \mathrm{~h}$, the $\beta$ treated condition refers to $\beta$ solution treatment $(1323 \mathrm{~K} / 1 \mathrm{~h})$ followed by quenching in oil and ageing at $823 \mathrm{~K}$ for $24 \mathrm{~h}$. Heat treatment in the $\beta$ phase field as well as the ageing treatment at $823 \mathrm{~K}$ for $24 \mathrm{~h}$ were carried out after vacuum $\left(10^{-3}\right.$ torr $)$ sealing of the blanks in silica tube along with turnings of titanium as gutter. Samples for optical metallography were etched with a solution containing by volume $5 \% \mathrm{HNO}_{3}, 10 \% \mathrm{HF}$ and $85 \% \mathrm{H}_{2} \mathrm{O}$ at room temperature and the microstructures were examined under Metallux-3 optical microscope. Tensile tests were carried out with cylindrical Hounsfield tensile specimens of gauge length, $15.4 \mathrm{~mm}$ and gauge diameter, $4.5 \mathrm{~mm}$, at a nominal strain rate of $5.6 \times 10^{-4} \mathrm{~s}^{-1}$. Standard cylindrical LCF specimens with gauge length, $15 \mathrm{~mm}$, and gauge diameter, $5.5 \mathrm{~mm}$, were machined from both as-received and $\beta$ treated materials. Gauge section of the machined samples was mechanically polished by $2 / 0$ to $4 / 0$ grade emery paper to remove the surface effect, if any. LCF tests were conducted over a wide range of total strain amplitude, in fully reversed $(R=-1)$ condi- 
Table 1. Chemical composition of the alloys, LT26A and IMI685 (wt.\%).

\begin{tabular}{lcccccccccc}
\hline Alloy & $\mathrm{Al}$ & $\mathrm{Zr}$ & $\mathrm{Mo}$ & $\mathrm{Si}$ & $\mathrm{C}$ & $\mathrm{Fe}$ & $\mathrm{O}$ & $\mathrm{N}$ & $\mathrm{H}$ & $\mathrm{Ti}$ \\
\hline LT26A & $6 \cdot 70$ & 5.90 & 0.53 & 0.26 & $0 \cdot 041$ & $0 \cdot 024$ & $0 \cdot 145$ & 0.0017 & 0.003 & Bal. \\
IMI685 & $6 \cdot 28$ & $5 \cdot 22$ & 0.53 & 0.25 & 0.080 & $0 \cdot 021$ & $0 \cdot 140$ & 0.0015 & 0.003 & Bal. \\
\hline
\end{tabular}

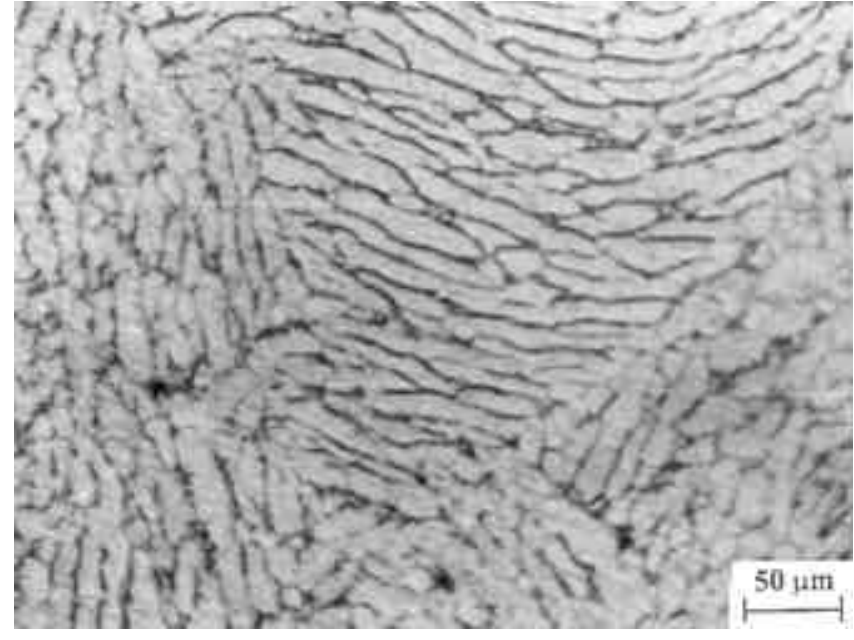

Figure 1. Optical micrograph showing microstructure of the alloy, LT26A, in the as-received condition.

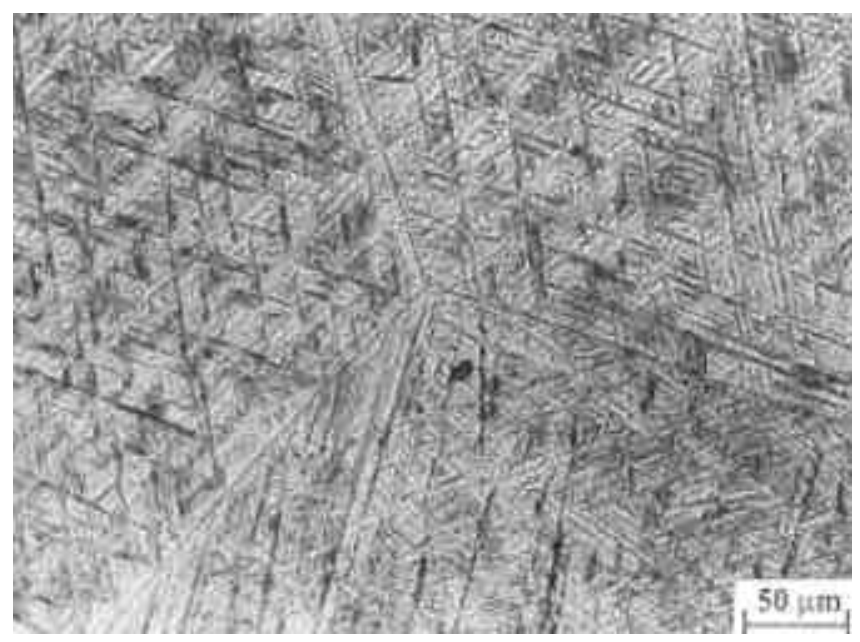

Figure 2. Optical micrograph showing microstructure of the alloy, LT26A, in the $\beta$ treated condition.

tion using triangular waveform at a frequency of $0 \cdot 2 \mathrm{~Hz}$ on a completely computer controlled servohydraulic MTS testing machine of $5 \mathrm{~T}$ capacity.

\section{Results and discussion}

The optical microstructure of the alloy, LT26A, in the asreceived condition is presented in figure 1. It shows mostly heavily deformed $\alpha$ grains along with some spheroidized $\alpha$. It was established by image analyser (VDIS-III) that average grain size of the $\alpha$ grains was $55 \mu \mathrm{m}$, though most of the grains were in the range $40-70 \mu \mathrm{m}$ and the form factor was $\sim 0.5$. In contrast, a basketweave structure of martensitic platelets of $\alpha$ may be seen in the $\beta$ treated condition (figure 2 ). The size of the prior $\beta$ grains was found to lie in the range $700-1600 \mu \mathrm{m}$ and the average grain size was measured to be $1200 \mu \mathrm{m}$. Tensile properties of the material in the two conditions are presented in table 2 . It may be seen that there is appreciable difference in tensile properties of the alloy in the two conditions. In particular, ductility of the material is much lower in the $\beta$ treated condition than that in the as-received one.

The variation of the average cyclic stress with number of cycles, at different total strain amplitudes, in the asreceived and $\beta$ treated condition is shown in figures $3 a$ and $\mathrm{b}$, respectively. It is obvious from the stress response curves that extensive softening at room temperature takes place in both the cases and the tendency for softening increases with strain amplitude. Nearly a stable cyclic stress response may, however, be seen at low strain amplitude $\left(\Delta \varepsilon_{\mathrm{p}} / 2 \leq \pm\right.$ $0.65 \%$ ) in both the conditions. Cyclic softening in the asreceived condition may be attributed to its initial microstructure resulting from hot forging. Worked metals and alloys are known generally to undergo cyclic softening because of rearrangement and partial annihilation of highdensity dislocations (Hertzberg 1976; Laird 1976). Cyclic softening in the $\beta$ treated condition may also be attributed to rearrangement of high density dislocations resulting from oil quenching following the $\beta$ solution treatment. In general, the degree of softening may be seen to increase with applied strain amplitude. The cyclic softening in both the as-received and $\beta$ treated conditions of the alloy, LT26A, is similar to that observed in the near- $\alpha$ titanium alloy, IMI685 (Eylon and Hall 1977). Cyclic softening observed in the present investigation is in accordance with the prediction of Dieter (1988), that metals with lower value of work hardening exponent $(n<0 \cdot 15)$ exhibit cyclic softening. Stress response is also known to depend on the ratio of monotonic UTS to $0.2 \%$ YS. Metals with $\sigma_{\mathrm{UTS}} / \sigma_{\mathrm{YS}}<$ 1.2 undergo softening while those with $\sigma_{\mathrm{UTS}} / \sigma_{\mathrm{YS}}>1.4$ exhibit cyclic hardening. The value of $n$ and the ratio of $\sigma_{\mathrm{UTS}} / \sigma_{\mathrm{YS}}$ for both the conditions are presented in table 2. It may be seen that according to the criteria for softening referred to above, cyclic softening should be expected in both the conditions.

Cyclic stress-strain curves plotted with cyclic stress and strain corresponding to half-lives are important means of 
Table 2. Tensile properties of the alloy, LT26A, in the as-received and $\beta$ treated conditions at room temperature.

\begin{tabular}{lcccccc}
\hline Material condition & $\sigma_{\mathrm{YS}}(\mathrm{MPa})$ & $\sigma_{\mathrm{UTS}}(\mathrm{MPa})$ & $\sigma_{\mathrm{f}}(\mathrm{MPa})$ & $\%$ elongation & $n$ & $\sigma_{\mathrm{UTS}} / \sigma_{\mathrm{YS}}$ \\
\hline As-received & 884 & 941 & 897 & 11 & 0.036 & 1.07 \\
$\beta$ treated & 1006 & 1089 & 1082 & 7 & 0.038 & 1.08 \\
\hline
\end{tabular}
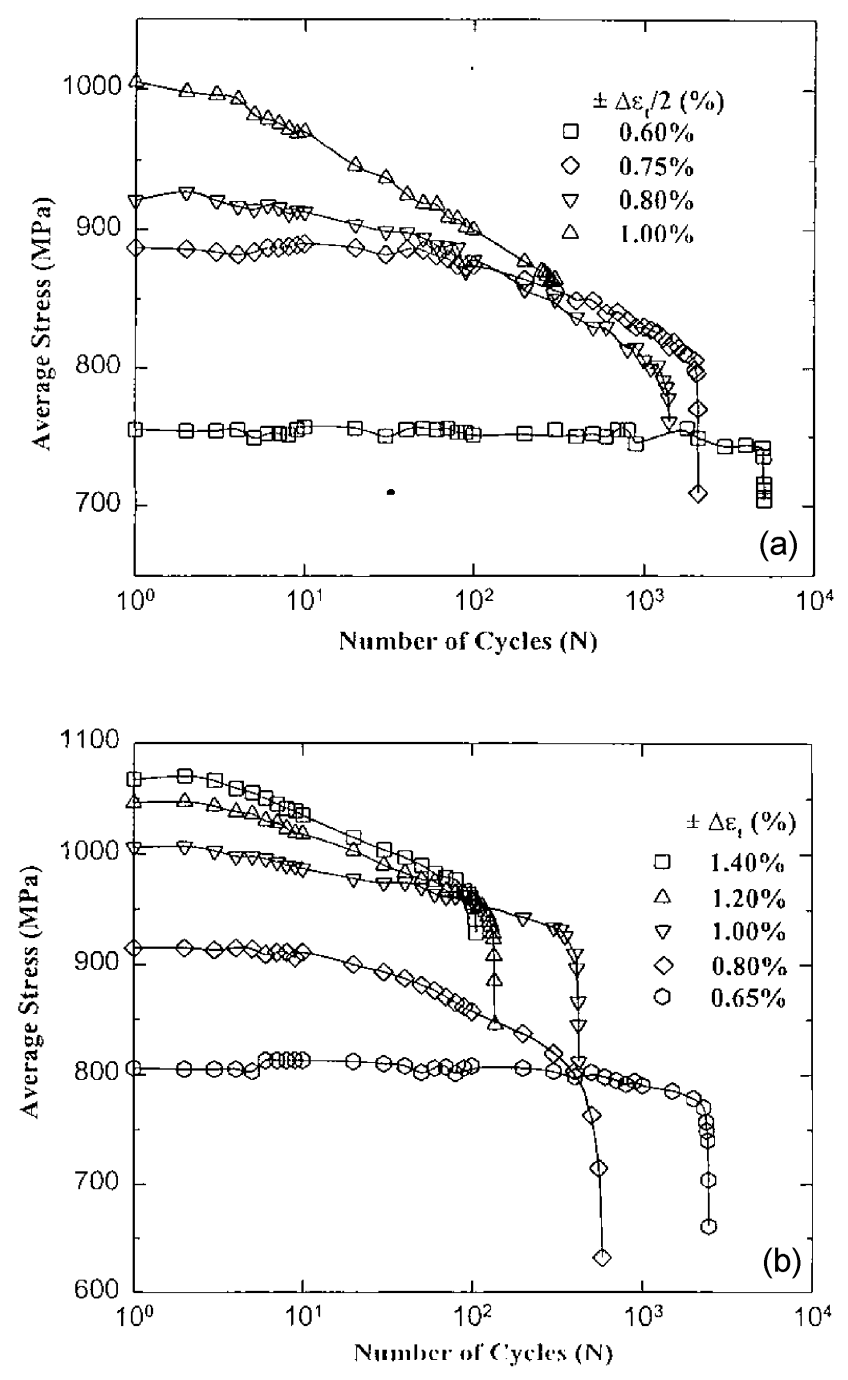

Figure 3. Variation of average cyclic stress with number of cycles for (a) as received and (b) $\beta$ treated conditions of the alloy, LT26A.

characterizing stress response of the material under cyclic loading. The cyclic stress-strain curves are shown in figure 4 along with the monotonic ones for both the conditions. It may be seen that cyclic stress strain curves lie below the monotonic ones for both the conditions, thus further strengthening the observations made on cyclic softening of the material. The larger difference in the levels of the monotonic and cyclic stress strain curves for the as-received condition as compared to the $\beta$ treated one is in conformity with the higher degree of softening in the former one, as
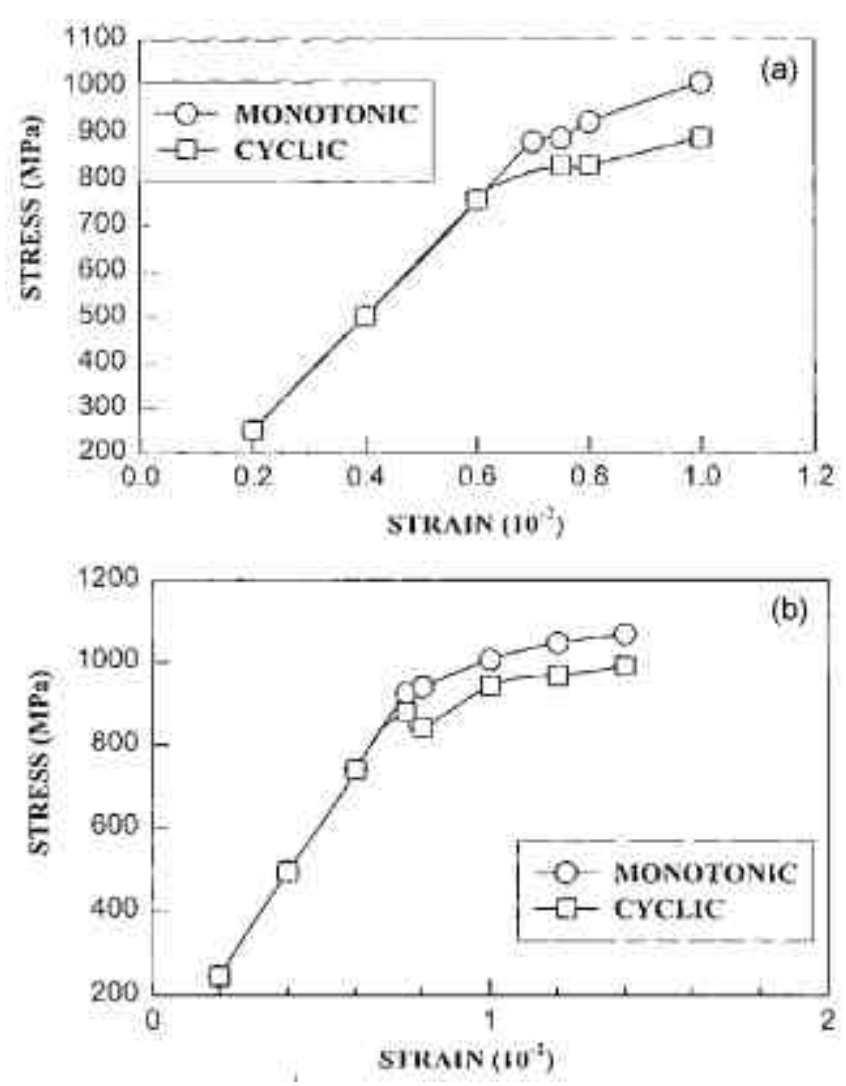

Figure 4. Cyclic and tensile stress-strain curves for the alloy, LT26A, in (a) as received and (b) $\beta$ treated conditions.

indicated by the stress-response curves in figures $3 \mathrm{a}$ and b. Some investigators have reported cross over in the cyclic and monotonic stress-strain curves above $1.5 \%$ of total strain in the near- $\alpha$ titanium alloy, IMI685 (Ramchandra et al 1988). However, in the present investigation, no cross over of the cyclic and monotonic stress-strain curves was observed up to the total strain amplitude of $\Delta \varepsilon_{\mathrm{t}} / 2 \leq \pm 1.4 \%$.

The variation of fatigue life, expressed as the number of cycles to failure, $N_{\mathrm{f}}$, with different components of strain amplitudes, is shown on the log-log scale in figure 5. Values of transition fatigue life were determined from intersection of the $\Delta \varepsilon_{\mathrm{e}} / 2$ vs $2 N_{\mathrm{f}}$ and $\Delta \varepsilon_{\mathrm{p}} / 2$ vs $2 N_{\mathrm{f}}$ plots. Comparison of fatigue life of the as-received and $\beta$ treated condition is shown in figure 6 by Coffin-Manson $(\mathrm{C}-\mathrm{M})$ plot $\left(\Delta \varepsilon_{\mathrm{p}} / 2\right.$ vs $2 N_{\mathrm{f}}$ ). It is obvious from the C-M plot that the as-received material exhibits higher fatigue life at lower strain amplitudes. The difference in fatigue life in the two conditions, however, narrows down at higher strain amplitudes. Also, the $\mathrm{C}-\mathrm{M}$ plots for both the conditions may be seen to 

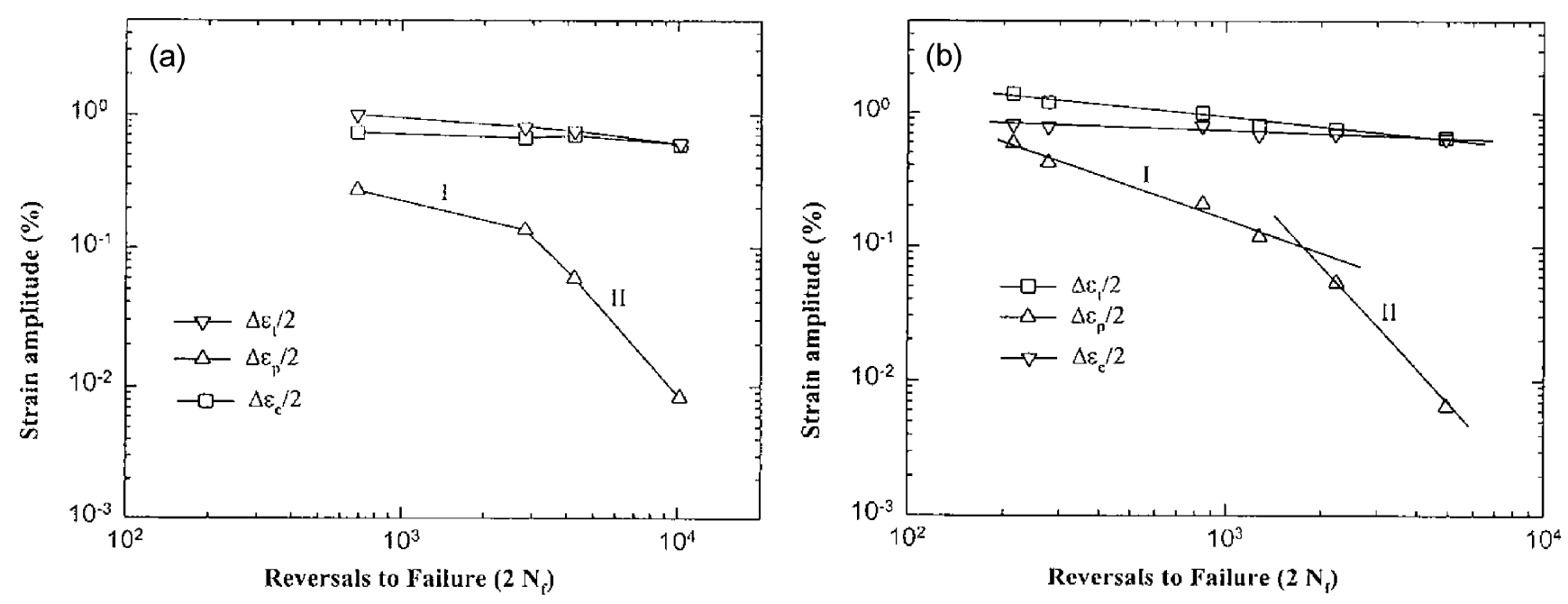

Figure 5. Variation of number of reversals to failure $\left(2 N_{\mathrm{f}}\right)$ with different components of strain amplitude at $R T$ for the alloy, LT26A, in (a) as received and (b) $\beta$ treated conditions.

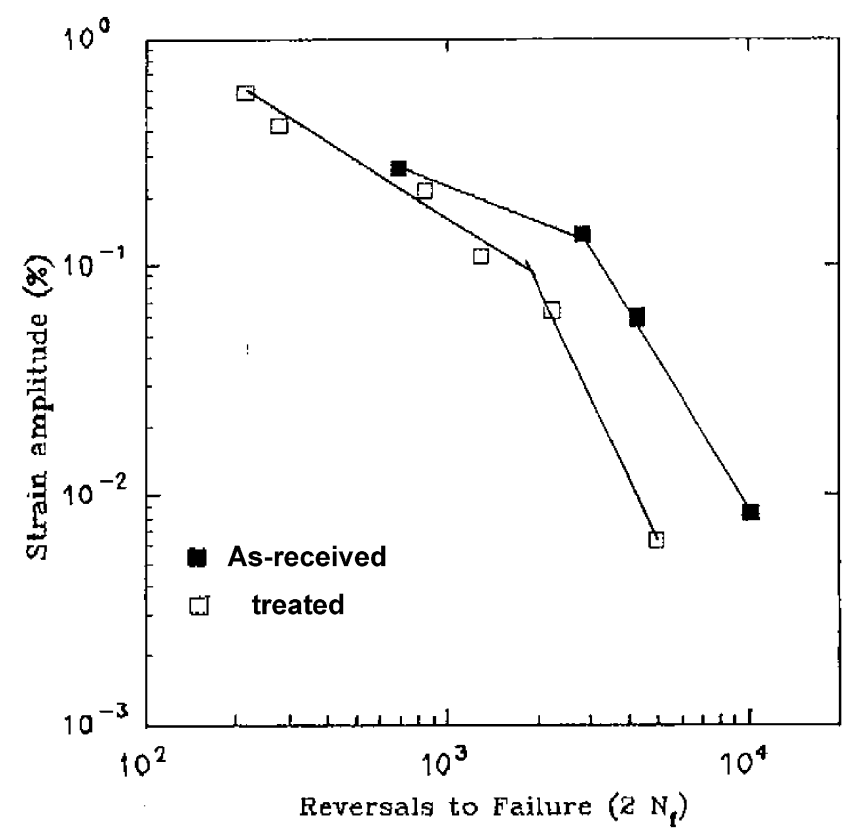

Figure 6. Variation of number of reversals to failure $\left(2 N_{\mathrm{f}}\right)$ with plastic strain amplitude at $R T$ for the alloy, LT26A, in as received and $\beta$ treated conditions.

Table 3. LCF parameters of the alloy, LT26A, in the as-received and $\beta$ treated conditions at room temperature.

\begin{tabular}{lcccc}
\hline Material condition & $\sigma_{\mathrm{f}}^{\prime}(\mathrm{MPa})$ & $b$ & $\varepsilon_{\mathrm{f}}^{\prime}$ & $c$ \\
\hline As-received & 1400 & -0.073 & 0.066 & -0.487 \\
$\beta$ treated & 1440 & -0.070 & 0.465 & -0.830 \\
\hline
\end{tabular}

exhibit bilinear behaviour. It may, however, be noted that there is no dual slope behaviour in the plot of $\Delta \varepsilon_{\mathrm{t}} / 2$ vs $2 N_{\mathrm{f}}$ (figure 5). The bilinearity in the $\mathrm{C}-\mathrm{M}$ plot may be attributed to planarity of slip and the consequent initiation of crack in the slip bands as established recently in the near- $\alpha$ alloy, IMI834 (Nidhi Singh et al 2002). The values of other LCF parameters viz. fatigue strength coefficient $\left(\sigma_{\mathrm{f}}^{\prime}\right)$, fatigue strength exponent $(b)$, fatigue ductility coefficient $\left(\varepsilon_{\mathrm{f}}^{\prime}\right)$ and fatigue ductility exponent $(c)$ are given in table 3 . It is known that in general, $\sigma_{\mathrm{f}}^{\prime} \approx \sigma_{\mathrm{f}}$ and $\varepsilon_{\mathrm{f}}^{\prime} \approx \varepsilon_{\mathrm{f}}$, where $\sigma_{\mathrm{f}}$ and $\varepsilon_{\mathrm{f}}$ are respectively true fracture stress and true fracture strain in tension. Based on the equation (Manson and Hirschberg 1964) given below:

$$
\Delta \varepsilon_{\mathrm{t}} / 2=\sigma_{\mathrm{f}}^{\prime} / E\left(2 N_{\mathrm{f}}\right)^{\mathrm{b}}+\varepsilon_{\mathrm{f}}^{\prime}\left(2 N_{\mathrm{f}}\right)^{\mathrm{c}}
$$

it is obvious that while low cycle fatigue life is governed by ductility of the material in high strain amplitude regions, strength controls the life at low strain amplitudes. The high fatigue life of the as-received material may thus be attributed to its ductility.

\section{Conclusions}

The following conclusions are drawn from the present investigation:

(I) Ti alloy, LT26A, shows significantly different microstructures in the hot forged (as-received) and $\beta$ treated conditions.

(II) There is considerable difference in tensile properties of the as-received and $\beta$ treated material. Ductility of the $\beta$ treated material is much lower than that of the as-received one.

(III) LCF life in the as-received condition is higher than that in the $\beta$ treated one. Bilinearity is exhibited in the C-M plots $\left(\Delta \varepsilon_{\mathrm{p}} / 2\right.$ vs $\left.2 N_{\mathrm{f}}\right)$ for the two conditions. 


\section{References}

Dieter G E 1988 Mechanical metallurgy (London, UK: McGraw Hill) p. 390

Eylon D and Hall J A 1977 Metall. Trans. A8 981

Eylon D and Bania P J 1978 Metall. Trans. A9 1273

Flower H M, Swann P R and West D R F 1971 Metall. Trans. 23289

Hertzberg R W 1976 Deformation and fracture mechanics of engineering materials (New York: John Wiley \& Sons) p. 415
Laird C 1976 Alloy and microstructural design (London: Academic Press) p. 175

Manson S S and Hirschberg M H 1964 Fatigue an interdisciplinary approach (Syracuse, NY: Syracuse University Press) p. 133

Nidhi Singh, Gouthama and Vakil Singh 2002 Met. Sci. Engg. A325 324

Ramchandra C, Verma V K and Singh V 1988 Int. J. Fatigue 1021 